\title{
The compatibility of drama language teaching and CEFR objectives - observations on a rationale for an artistic approach to foreign language teaching at an academic level
}

Filippo Fonio, Geneviève Genicot

\begin{abstract}
The elaboration of the rationale proposed here finds its roots in an examination of the CEFR (Common European Framework of Reference for Languages) parameters. We are notably interested in highlighting the importance of artistic practice - and in particular of drama performance - in the context of foreign language learning. We are thus proposing here considerations concerned with the estimation of artistic practice as a specific way of teaching and learning foreign languages. Our usual target group consists of Bachelor and Master students interested in learning Italian through drama techniques but whose subject is not primarily Modern Languages (non-specialist students). By proposing a set of standard skills that match CEFR parameters with artistic pedagogy training, we intend to promote valuable criteria for teachers, learners and examiners in order to promote language learning through artistic practice syllabi.
\end{abstract}

\section{Introduction}

By reflecting upon a rationale for learning languages through artistic practice, we attempt to establish the legitimacy of drama as a tool in foreign language teaching workshops/classrooms. The overall acceptance and adoption of the Common European Framework of Reference for Languages (CEFR) parameters in recent years, even if not universally acknowledged, highlights a certain demand for European uniformity in language teaching; this is why systematic work on the use of drama practice in language classrooms is, in our opinion, needed nowadays. We hope that our European colleagues will find in this rationale, which is intended to match CEFR parameters with artistic practice in teaching foreign languages, a useful tool for language courses on a peer-level basis. We also hope that showing connections between language teaching, European demands and drama pedagogy in the language classroom 
will encourage colleagues who are used to more traditional methods and unfamiliar with drama, to try out different ways of teaching foreign languages by introducing drama components into their classrooms.

This paper starts with a few remarks that depict the institutional context we are working in. It then presents, in thematic sections, analyses of a series of CEFR fundamentals (socio-political intents, pedagogical concepts, competences and competencies). The aim is to show, and to explain at the same time the project in which we are engaged: we think that there exists a point of convergence between the CEFR and drama practice that needs to be researched in depth.

\section{Context}

The considerations presented here are rooted in our teaching experience as well as in our personal areas of competence: those of an Italian language teacher who has, for the last three years, taught Italian through drama practice for non-specialist students, and of a playwright and director who has also taught French as a foreign language.

Our local-based experience is necessarily linked to the context we are working in, i.e., Grenoble University Department of Applied Linguistics for Non-Specialist Students (LANSAD). In this respect, the distinction between two different types of programs is crucial. Foreign language classes in French universities target non-specialist and specialist students in distinct ways. Non-specialist students are the ones whose major is not primarily Modern Languages, and it is for them that our Italian classroom through drama practice is primarily designed (although it can also be attended by specialist students, e.g., Italian Literature and Civilisation, LLCE, students, or Italian as an Applied Language - LEA students). Specialist students (i.e., specializing in one of the languages taught at Grenoble university, including Italian) have specific drama classes that focus more on literature, whereas the drama classes of non-specialist students focus primarily on language in use. Moreover, LANSAD language courses, as principally addressed to non-specialist students, are usually based on actionoriented approaches, which sometimes come close to drama practice exercises. The activities are mostly based on spoken conventions and conversation, with a strong interest in sociolinguistic features in contemporary language.

For both specialist and non-specialist students, drama language classes represent one of the many options in their choice of core elective courses that they have to integrate into their study program, selecting them from fields other than their main subject. Nevertheless, students attending these classes do not obtain language credits (which every student has to get in order to complete his or her academic year) but merely optional credits. For this reason, group opening in the drama class is not always guaranteed (LANSAD groups open with a minimum of 7 students attending the course, at least 4 of them being non-specialist students) because of a possible lack of students interested in a class not offering language credits. At the same time, students applying to the class generally show strong motivation and/or drama interests. 
Our Italian through drama class is a two-term course consisting in one two-hour meeting per week for 24 weeks. The students attending our atelier generally come from Science or Social Sciences (e.g., Business, Law, Biology), as well as from Humanities (with subjects as diverse as Modern Languages, History, Art History, Philosophy, Drama Studies). The simultaneous presence of specialist and non-specialist students in LANSAD drama language classes is certainly an enriching experience both for teachers and students since students come with different backgrounds depending on their main subject, enhancing the dynamism in the group.

Finally, we would like to point out that what is presented here are preliminary remarks with the aim to realise a level-based rationale for language learning through drama practice. Our research is supported by an international and interdisciplinary team and aims to propose a set of standard skills, based on the CEFR foreign language learning competencies, the acquisition of which is facilitated by drama language courses. In the next part of the paper, we will draft the conceptual and theoretical background for the realization of the pedagogical framework. The last part of the paper will offer a series of examples and linguistic categories of analysis identified as useful to the creation of a rationale.

\section{A series of convergencies between CEFR fundamentals and drama practice}

\subsection{The socio-politics of multiculturalism}

An important aspect of CEFR that should encourage foreign language teachers to promote drama practice in the classroom is its socio-political intent, namely the explicit promotion of universal values such as democracy, interculturalism and the encounter with other people - which can easily be put into correspondence with the drama tradition of dialogue and debate. The authors of the CEFR refer to the Council of Europe principles, stating that "the overall aim of the Council of Europe [is] to achieve greater unity among its members and to pursue this aim by the adoption of common action in the cultural field" (CEFR: 2). Without reducing drama practice to a mere tool that serves political European objectives, we stress that allowing students to acquaint themselves with other realities through language and culture is one of the best ways to guarantee mutual acceptance and respect, which are objectives that are pursued by EU politics to combat xenophobia. In this respect, applied drama techniques are probably one of the best ways to acquaint language learners with the other (and the Other), and this in, at least, two ways: first, a drama-based language class is much more likely to develop as a group than the students of a more traditional language course; second, by the use of literary texts. Literary texts are filled with linguistic and cultural elements that, when considered by a foreign learner, become multilingual and multicultural elements. In our specific case in Grenoble, we also allow students to work with contemporary Italian 
playwrights, which only enriches the cultural exchange.

\subsection{The concept of rationale}

Originally conceived as a human resource tool that helps program designers to define professional training objectives, the rationale was subsequently extended to teaching practice. Here is one recent definition of the rationale which suggests its uses as a pedagogical device:

La notion de référentiel renvoie à celle de compétences, y compris en didactique des langues. Un référentiel est un inventaire, une liste descriptive des compétences nécessaires pour une fonction, un métier, etc. ${ }^{1}$ (Robert, Jean-Pierre; Rosen, Evelyne 2010: 237)

In this definition, the notion of a descriptive inventory of competences proves to be particularly useful for a specific professional or pedagogical objective. This notion accounts for the deep associations between rationales as learning devices and the CEFR. The Common European Framework of Reference, set up in the early 1990s by a mainly European Union team ${ }^{2}$ as a global tool aimed at harmonising language programmes and syllabi in the different European countries, has indeed been primarily conceived of as an inventory.

In their Foreword, the authors present the CEFR as a sort of toolkit offered to the reader, who is strongly encouraged to apply it to new fields, just as we are doing by attempting to apply the CEFR theoretical framework and approaches to language learning through drama practice. One of the reasons justifying this attempt is the fact that theatre is, amongst other things, a complex and composite communicative device, implying and bringing into play different components of the communication process. Language, both verbal and non-verbal (a distinction that we will explore later) obviously plays a fundamental role in this communication process.

The CEFR approach to human language is taxonomic, trying to overcome its complexity by dividing the compound nature of language and communication into skills or competences: "The taxonomic nature of the Framework inevitably means trying to handle the great complexity of human language by breaking language competence down into separate components." (CEFR: 1) This taxonomic model can prove useful in order to describe language learning through applied drama techniques. Nevertheless, at this early stage of the research, we will not take into account the overall CEFR parameters. Instead, we will show, by means of thematic and synthetic entries, how CEFR represents a powerful tool for legitimating our language drama practice. The fundamental question we will answer is this: how can we show that teaching languages through drama practice matches CEFR objectives?

\footnotetext{
1 "The notion of a set of standard skills points to the notion of competences, also to language didactics. A set of standard skills is an inventory, a descriptive list of the competences needed in order to accomplish a function, a job, etc."

2 Canada also participated in this project as an external observer; and the Swiss team's reflections were of a primary importance.
} 


\subsection{The pedagogy of tasks}

One aspect of CEFR pedagogical features compatible with our practice is the key-concept of task, upon which the CEFR action-based approach depends. The presence of tasks, i.e., "actions [...] performed by one or more individuals strategically using their own specific competences to achieve a given result" (CEFR: 9) is easily recognizable in drama practice, and particularly when staging plays. Every drama production includes many different phases of rehearsal during which a large amount of different tasks have to be accomplished. Instructions about the tasks are given in Italian within a concrete situation. In language drama class, the learners' motivation to interact stems from the fact that they have to accomplish the tasks in a very specific way, because other more complex tasks - and the final performance itself - depend on their accomplishment.

\subsection{The communicative paradigm}

Promotion of the communicative paradigm is the first notable aspect of the CEFR approach to language teaching and learning (CEFR: 9-10), together with the importance of designing language courses suited to the learners' real needs. According to the authors, the focus on such pragmatic aspects would allow learners to improve their professional mobility within EU member countries.

Listing the main aspects of the CEFR approach to second language learning is useful in order to understand how well these criteria can be realized in drama for foreign language learning. The CEFR approach stresses the importance of the following principles:

- Contents of learning should be connected to everyday life situations;

- Language learning should aim to exchange information and ideas;

- Foreign cultural contents, particularly regarding lifestyles and habits, should be placed at the center of the learning process - authentic pedagogical supports being crucial in this respect.

These principles match, partly or fully, constitutive dimensions of some of the most common drama practice aspects:

- Using scenarios and creating dramatic interactive situations

- Using dialogue to put different streams of ideas into debate

- Studying the cultural contents of scripts during the dramaturgical analysis preliminary to any serious stage direction work

Communicative aims are at the centre of the CEFR approach to language learning: learners learn a foreign language through communication. Drama 
practice precisely enhances the development of communicative competencies because it offers learners a plot, or at least a situation (perhaps not always an everyday-life one, but surely one that exists in a defined world having its own rules, even if absurd or located in a different time or space), and acting out this situation provides a reason for language, both verbal and non-verbal.

Drama practice, in other words, also works as a means of bringing learners literally into play by confronting characters with situations that are plausible (for each drama universe considered) and concrete (something has to happen even if nothing happens, this nothing must happen dramatically and concretely - because drama is to be seen, as is shown by the etymology of the word theatre, i.e., teatron, the place where you can see from). Theatrical practice thus offers a staged life ersatz that allows learners to use the linguistic skills necessary in a situation simulating real life, compensating for the fact that language classes take place in a foreign country. The choice of sociolinguistically dense plots (as we will see further on) gives the teacher the possibility to approach concrete communicative situations that exchange students in immersive language contexts can meet daily.

This approach corresponds exactly with the action-based pedagogy proposed by the CEFR, which considers foreign language learners as "social agents [...] who have tasks (not exclusively language-related) to accomplish in a given set of circumstances, in a specific environment and within a particular field of action." (CEFR: 9) Different authors state that drama provides these sets of circumstances and specific environments. According to Jean-Marie Schaeffer,

[d]ès lors qu'on se situe à l'intérieur du cadre fictif, [...] les actes de langage représentés, donc ceux des personnages, sont des actes sérieux qui les engagent comme nos actes nous engagent dans la vie réelle. ${ }^{3}$ (1999: 746)

In addition, semiotic approaches to drama are often focused on the concept of the actor's (and for us, the learner's) shared contexts, dramatic situation being a "progression dynamique d'actes de langage en interaction" (Ducrot, Oswald; Schaeffer, Jean-Marie 1999: 746). As for the central role of dialogue and its particular textual status: "le dialogue théâtral est un texte destiné à être, non seulement dit, mais agi en situation"5 (Ducrot, Oswald; Schaeffer, Jean-Marie 1999: 748). The use of dramatic dialogues during language classes, either through reading aloud or through performing, may in fact rejuvinate traditional approaches to oracy competencies (in this context note that O'Toole, John; Stinson, Madonna; Moore, Tina (2009: 49-ff.) propose to look at aspects of language learning through drama focused on spoken skills in a more systematic fashion).

\footnotetext{
3 "From the moment that we find ourselves inside of the fiction framework [...] the language acts that are represented, that is, the ones of the characters, are serious acts that commit them exactly as our acts commit us in the real life."

4 "Dynamic progression of language acts in interaction."

5 "Drama dialogue is a text destined to be, not only spoken, but also acted, in a situation."
} 
Moreover, a product-oriented approach to drama in education (see in particular Moody, Douglas J.: 2002) - the approach that we adopt in our Italian courses - adds to the "seriousness" of creating life-like situations and of the students' approach to drama practice itself. Staging dramas in a foreign language, that is performing in a foreign language in the strong sense of the word, represents, in fact, a concrete objective for learners. Anticipating the final performance in front of an audience, students rehearse with the seriousness of children at play; play which, as we know, is one of the best ways to learn.

\subsection{Plurilingualism}

The CEFR promotes a plurilingual attitude towards languages, which represents an innovative approach if compared to the traditional multilingual skills aimed at in language teaching and learning (see the debate summarized by Krzak, Michel 2009). Plurilingualism tends not to isolate an individual's knowledge of different languages into independent parts but to establish interconnections between these and allow the learner to develop partial skills (aimed, for example, at just understanding and not speaking the foreign language).

Linguistic aspects of mutual intelligibility: Plurilingualism is strictly intertwined with another public-spirited principle of the European Union, which is mutual intelligibility. Linguistic mutual intelligibility (and the consequent potential for comical unintelligibility and puns) is a commonplace drama device that allows us to connote dialogues by underlining social differences - let us think, for example, of commedia dell'arte - and, at the same time, to mimetically mirror multicultural society. The Italian dramatic tradition actually offers a large amount of pedagogically useful texts and plot outlines that put plurilingualism into play, as the need for mutual intelligibility on stage as well as in the audience.

Linguistic mutual intelligibility is, of course, a fundamental aspect of everyday life when teaching and learning foreign languages, in as much as learners' interlanguage, if considered in its expressive components, may be seen as a form of grammelot. Drama offers a large number of concrete contexts in which linguistic mutual intelligibility is a crucial element. We are referring to the great number of plays which are bilingual or actually stage linguistic mutual intelligibility (for example, characters who find themselves in situations of mutual intelligibility, or miscomprehension, because of travelling, living abroad etc.).

Bodily aspects of mutual intelligibility: Teaching foreign languages through drama practice also favours physical mutual intelligibility. With this generic label, we are referring to mutual intelligibility through the body and gestures, that is to say the overall aspects considered by proxemics. The capacity to handle such elements fluently when speaking in a foreign language is essential, and the CEFR considers, even though briefly, bodily and gestural language as part of the learner's "existential competence" (see CEFR: 11), underlining socio-cultural 
aspects of these languages. Pointing out the importance of the learner's need to acquire such skills, the CEFR provides this typical example of gestural intercultural misunderstanding and of the cultural specificity of body language: "the way one member of a specific culture expresses friendliness and interest may be perceived by someone from another culture as aggressive or offensive" (CEFR: 12).

The brief way in which the CEFR covers the learner's proxemic skills remains impoverished though. Moreover, the proxemic skills are considered as objects of progressive learning through the language proficiency levels A1 to C2, whereas drama approaches to foreign language learning show the fundamental importance of body language and non-verbal communication, especially for less equipped learners ("basic users", A1 to A2; see CEFR: 23).

Foreign language drama practice urges learners to improve their ability to communicate reciprocally through body language insofar as stage plays bring text to life through the movements of the learner's body in every physical dimension. The teacher's role here is fundamental in making students aware of the existence and importance of the physical dimension in foreign language, in transmitting proxemic knowledge and skills to them, and, finally, in giving them stage directions that fully develop these physical components.

\subsection{Pluriculturalism: through the text}

The promotion of plurilingualism by the European Union aims, in the last instance, at the development of pluriculturalism. The idea upon which this assessment is based is a culturalist notion of language: the cultural dimension of language as well as the strong relationship between culture and text cannot and should not be neglected:

Text is any sequence or discourse (spoken and/or written) related to a specific domain and which in the course of carrying out a task becomes the occasion of a language activity, whether as a support or as a goal, as product or process. (CEFR: 10; see also CEFR: 93-94)

In our case, texts are plays. The literary and textual dimensions of plays are among the most important aspects of a "product-oriented" foreign language drama atelier. It is probably the first thing that comes to mind when thinking of "product-oriented" drama courses: teachers help or coordinate students in selecting, close-reading, staging, rehearsing and, finally, performing a play.

The textual dimension of a play remains an essential one, even though foreign language teaching and learning through drama practice does not limit itself to textual analysis, and even if borderline cases of foreign language classes through mime and pantomime exist and are often very useful (especially if they are combined with other pedagogical approaches). Is it also important to point out that we are currently dealing primarily with dialogical theatre tradition, as far as our pedagogical experience is concerned. However, in doing so, we remain fully conscious that drama dialogue, as Jean-Marie Schaeffer (1999: 747) underlines, 


\begin{abstract}
"n'est pas la reproduction d'un dialogue naturel" but the "représentation artistique d'un tel dialogue, c'est-à-dire que non seulement il est indissociable d'une stylisation mais encore et surtout il est guidé en sousmain par des considérations d'efficacité dramatique qui renvoient à des problèmes typiques de la communication théâtrale". ${ }^{6}$
\end{abstract}

Moreover, staging a foreign language play that presents a certain degree of linguistic and cultural thickness offers the teacher a series of possibilities when working with students to adapt (part of) the text, to readjust its dialogues for a certain audience, or to study cultural materials from the same area or tradition which could enrich the staging or clarify difficult scenes.

Learning foreign languages by the means of drama practice offers students a chance to develop these plurilingual and pluricultural skills. In order to stage a foreign language play, students have to decode its cultural component first, thus passing through a dramaturgic analysis process. The learner's acquisition of this cultural dimension can lead to the improvement of sociolinguistic skills in a foreign language.

A question upon which it is not possible to linger here, but which should at least be mentioned, is that of the teacher at the beginning of the class: which play should I choose? This choice is of fundamental importance as it can influence, in a positive or negative way, the work of a whole semester or even a year. From a cultural point of view, a contemporary text will probably provide the student with a more up-to-date cultural content, on the other hand older texts sometimes contain cultural elements that can help to understand aspects of contemporary society.

Let us share here the successful experience of the 2010-2011 academic year. With a group of 11 students we adapted and staged a 2009 comic play by the young Italian playwright Giovanni Allotta: Cercasi marito pensionato... importante che muoia subito. The main reason for choosing this text was the opportunity for introducing students to the cultural stereotypes that pervade Italian daily life, humour, habits, etc. We chose a contemporary popular comedy, which had originally been written in Sicilian dialect. The situation of women, the importance of virginity in Southern Italian society, greed amongst the popular milieu, etc. are just a few examples of cultural themes that we had the chance to work on with the students. The play also provided great opportunities for students to improve their proxemical skills through the learning of typical gestures, regional language habits and tics. It proved very useful for our students to attend a two-day workshop led by the author himself, which resulted in a real work in progress because of the fact that Cercasi marito... had never been staged before.

The strong cultural element of this artistic and linguistic practice results in a form of learning very close to the CEFR principle: "Knowledge of the shared

\footnotetext{
6 "Is not the reproduction of a natural dialogue" but the "artistic representation of such a dialogue, meaning that it is not only inseparable from stylization, but also and more importantly that it is guided by considerations regarding dramatic effectiveness, related to typical problems of drama communication."
} 
values and beliefs held by social groups in other countries and regions, such as religious beliefs, taboos, assumed common history, etc., are essential to intercultural communication" (CEFR: 11). This experience seems to suggest that genre differences are as important as period specific ones when it comes to choosing a text to be staged, and that it might be a good idea to work with popular or comic dramas.

However, we do need to collect more data about language drama experiences in other universities in order to come to any conclusion on this matter. Moreover, let us recall that the choice of the text also determines a specific textual typology that will allow learners to improve specific linguistic skills; these should thus be identified carefully by the teacher in order to ensure that the experience will suit the learner's needs. For example, the mimetic reconstruction of peasants' and popular milieu in Allotta's play resulted in an enriching linguistic and cultural journey which proved to suit intermediate to advanced learners particularly well, while lower proficiency students (only two out of eleven in the group) had to make a greater effort in order to familiarise themselves with the cultural aspects of the play.

\subsection{Written production: there is a lot more than staging a play in drama practice}

Of great importance for language learning is the fact that practicing drama in a foreign language through a product-oriented approach is more than merely close-reading a text intended for staging and thoroughly comprehending its meanings. One of the aims of a product-oriented foreign language artistic course might be, for example, the production of a play or the adaptation of a pre-existing text.

In order to gauge the pedagogical benefits involved let us look at an example. During the academic year 2008-2009 we worked with a group of 19 students on the adaptation of Rossana Campo's contemporary novel Mai sentita così bene, which became a sort of literary and cultural pastiche called (Quasi) mai sentita così bene.

Generally speaking, drama language courses offer the teacher the chance to work with activities which precede and follow the text. They give him or her the possibility to propose to students both oral and written activities that involve production, comprehension, repetition and rehearsal through the different proficiency levels formalized by the CEFR. Different kinds of activities can be proposed following a sequential model that allows enacting the CEFR concept of "variable geometry" (see CEFR: 175). Let us suggest some of these possible activities:

- Analysing a written text, which constitutes the starting point for oral improvisations;

- Practicing oral production in Italian through free or guided improvisations; 
- Starting from oral improvisations, on which basis it would be possible to create an original written text;

- Adapting a pre-existing text by reformulating, simplifying, contextualising or transforming it by the means of intersemiotic translation (e.g., from film, novel, comics into a play).

- For example, the adaptation of Rossana Campo's novel started with the close reading of each chapter of the book followed by a mimic improvisation and by a spoken improvisation with the aim of portraying the characters and of familiarising the students with them. As soon as chapters became scenes through the adaptation proposed by some of the students, the rest of the group immediately rehearsed them, so as to allow the playwrights to rework their scenario. Moreover, words, sentences, dialogue portions and characters were reemployed in improvisations on slightly different subjects in order to consolidate the learning.

\section{Linguistic thickness of drama practice}

In this last section of the paper, we will focus on some of the linguistic dimensions upon which a product-oriented foreign language drama course is based, with particular attention to the language learning aspects that the teacher can improve during the staging of a play, i.e., linguistic features, sociolinguistic features, pragmatic and paralinguistic features. Examples will be given with reference to the above-mentioned play staged with the 2010-2011 academic year students.

\subsection{Linguistic features}

With reference to linguistic features, phonetic learning is a fundamental part of foreign language courses through drama. One of the main tasks of the teacher in general is to transmit to students a correct, or normative, pronunciation. It is sometimes useful to repeat the same words and sentences over and over during the class, and especially during rehearsals. By doing so, the student's phonetic (and musical) awareness and self-confidence are developed further. Moreover, pronunciation practice can contribute to a long-lasting form of knowledge, rooted in an active body in a concrete, even if pretend, situation. The annoying corrections and repetitions, though necessary for the students with phonetics difficulties, also become more bearable in the face of preparing for a show, and the wish to be ready on the day can help to give the student more motivation in these situations.

However, normative pronunciation is not always the aim when staging dramas. Working on phonetic features might thus envisage proposing activities that can help students to become aware of phonetic and phonological variation and of its sociolinguistic value. 
An important part of the process of phonetics learning often consists in exposing students to varieties of pronunciation, phonetic inabilities, regional phonetics, conversational habits or verbal tics. For example, amongst the characters in Cercasi marito pensionato... is a lisping man with a strong Southern Italian and common accent. In order to familiarise students with these phonetic elements, we started by playing a series of videos and audio recordings that featured lisping characters or Southern Italian speakers, followed by self-recorded versions of the same dialogues with no lisping or in standard Italian pronunciation. In the case of the play by Giovanni Allotta this proved to be particularly important, because many of the play's jokes and puns are based on linguistic misunderstandings due to ambiguous word pronunciation.

Syntactical phonetics is also very important when it comes to staging culturally dense plays. In particular, a challenging and enriching part of our work is to contribute to overcoming stereotypes of the Italian language and to introduce students to the real musicality of Italian. One of the skills that we normally try to develop is a sensitivity to harmonious phrasing to be acquired, amongst other activities, by repeated chanted readings, tongue-twisters and riddles, nursery rhymes, etc.

Not to be neglected are prosody and intonation, because:

la prosodie a un double rôle: d'une part elle contribue à l'organisation syntaxique et discursive du discours, et d'autre part, en tant que gestuelle vocale, elle permet l'expression des attitudes et des émotions dans une langue donnée. ${ }^{7}$ (Ducrot, Oswald; Schaeffer, Jean-Marie 1999: 411)

For example, in Cercasi marito..., different intonations convey different meanings for many lines, and mistaken comprehension of parts of the text provoked mistaken intonations (e.g., single questions like "Che hai che piangi?" were sometimes mistakenly understood as double questions: "Che hai? Che piangi?", especially when marked syntax interferes with a normative perception of word order in Italian).

\subsection{Sociolinguistic features}

Drama is a particularly effective way to help students become aware of sociolinguistic features. Activities we offered during the academic year we are referring to were useful to familiarise students with:

- Language registers (for example, the main character, who is very sensual when wanting to seduce potential allies, but extremely vulgar when she speaks to herself or to her servant);

- Vertical and horizontal social relations between the play characters (for example, conversations held between masters and servants, between peasants, etc.);

\footnotetext{
7 "Prosody has a double function: it contributes to syntactic and discursive organization of speech, and at the same time, as does movement for the body, it allows the voice to express attitudes and emotions in a given language."
} 
- Gendered linguistic elements (for example, the feminine stereotypes identifiable in the language of the servant or of other simple women);

- Differences in the characters' ages (for example conversations held between the old husband and the young wife);

- T-V distinctions (i.e., linguistic markers of social relations, politeness conventions such as tu/lei/voi, etc).

- One of the most interesting aspects of the CEFR approach to foreign language teaching and learning is the great importance it gives to sociolinguistic components of foreign languages (see in particular CEFR: 13 on T-V distinctions and CEFR: 118-ff. on politeness conventions).

\subsection{Pragmatic and paralinguistic features}

Non-verbal linguistic features are important as well, and it is not always an easy task to familiarise students with the pragmatic and paralinguistic aspects of staged plays. Examples of elements we are constantly dealing with are: irony and humour, parody, discourse interactions, perlocutionary acts, cohesion and coherence - not only at the textual level, but also with regard to the coordination between verbal and non-verbal features - mimics, gestures and proxemics. Interestingly, full comprehension of some features (for example, the deep meaning of a joke) only comes with time: we have so often witnessed the moment when a student's eyes suddenly light up with the understanding of the meaning of a line during a rehearsal, even if they already memorised their text several weeks ago. Incidentally, shyness should not be underestimated when it comes to comprehension problems. In more traditional and grammar-oriented pedagogical approaches to foreign language teaching, students are able to study lots of words and expressions that they do not fully understand without ever asking anything about them. With long-term projects, such as staging a play, this does not happen, first because you cannot act in a convincing way if you do not understand what you are saying, and second because the repetition of the line and the situation creates a compelling pragmatic device for the student; in order to feel at ease on the stage, he or she has to fully understand every line and joke. All this allows students to build sound linguistic knowledge and achieve full comprehension.

\section{An open conclusion...}

One final aspect of the CEFR suggestions for foreign language pedagogy, which we are currently working on and which is an essential one, is evaluation. The main problem, which is not an easy one, is answering the question: should foreign language courses through artistic practice be:

- a form of linguistic evaluation; 
- an evaluation that should be based on artistic or aesthetic aspects;

- a mixed form of evaluation which takes into account both linguistic and artistic elements?

Our linguistic and artistic practice so far suggests that in order to allow teachers to evaluate a student's proficiency and progress made during the whole academic year, a linguistic-based form of evaluation is the best solution. Nonetheless, aesthetic aspects should not be completely put aside if we consider drama language courses not merely as a tool for language learning but also in terms of theatrical practice in foreign language. As for a solution to the problem of the evaluation criteria, we believe that once competencies and activities are listed, and relative tasks established, the accomplishment or non-accomplishment of the tasks themselves will help teachers in evaluating students both on an artistic and on a linguistic plane.

As we have shown, we are convinced that there exists a synergy between our approach to language teaching through drama practice and the CEFR main objectives. The CEFR could thus represent a powerful ally for the legitimization of drama practice amongst the other traditional methods in foreign language teaching. Such legitimization could also mean institutionalization in an academic context, which is crucial to a lot of us language course teachers. Moreover, the arguments developed in this paper represent an attempt to revise previous scholarship which tends to underline the hiatus between drama pedagogy and the CEFR approach to language learning. ${ }^{8}$

We are grateful to Christopher Mitchell, Kathy Hatch and Mandy Collins for their linguistic assistance.

\section{Bibliography}

Council of Europe (2001): Common European Framework of Reference for Languages: Learning, Teaching, Assessment. Online English version available at: http://www.coe.int/t/dg4/Iinguistic/Source/Framework_EN.pdf

Ducrot, Oswald; Schaeffer, Jean-Marie (1999): Nouveau dictionnaire encyclopédique des sciences du language. Paris: Seuil

Moody, Douglas J. (2002): Undergoing a Process and Achieving a Product: A Contradiction in Educational Drama? In: Bräuer, Gerd (ed.): Body and Language. Intercultural Learning Through Drama. Westport (Connecticut), London: Ablex Publishing, 135-159

Robert, Jean-Pierre; Rosen, Evelyne (2010): Dictionnaire pratique du CECR. Paris: Ophrys

\footnotetext{
8 See, for example, Schmenk (2004: 13) who states: "With respect to drama pedagogy, it is impossible to generate arguments from the CEF that would help us promote the use of drama in the language classroom."
} 
O’Toole, John; Stinson, Madonna; Moore, Tina (2009): Drama and Curriculum. Heidelberg: Springer

Schmenk, Barbara (2004): Drama in the Margins? The Common European Framework of Reference and its Implications for Drama Pedagogy in the Foreign Language Classroom. In: GFL - German as a Foreign Language 1, 7-23

Zrzak, Michel (2009): Politique des langues dans l'Union Européenne. Le multilinguisme en question? In: D’Aligny, François-Xavier; Guillaume, Astrid; Nieder, Babette; Rastier, François; Tremblay, Christian, Wismann, Heinz (eds.): Plurilinguisme, interculturalité et emploi: défis pour l'Europe. Paris: L'Harmattan, 352-356 